\title{
Challenges of Open innovation in the Tourism Sector
}

This study shows how the tourism sector is applying the new paradigm of open innovation supported by social media. We drew on a sample of 135 companies from the sector in the south of Portugal and Spain to perform a cluster analysis. Currently open innovation is a challenge in tourism, and social media are a strategic tool. The main objective is to evaluate the impact of customer involvement in innovation performance. The results show positive impact of open innovation in New Product Development (NPD) moreover results derived in terms of turnover and competitiveness improves, however it all depends on the innovation management model. Anyway, even today formal adoption is still pending to achieve the desired outcomes but this research highlights how the sector is advancing in the direction of open Innovation.

Keywords: Open innovation, New Service Development (NSD), Social media, Tourism sector, Co-creation environment.

\section{Introduction}

Currently, innovation is a strategic element of competitiveness (OECD, 2013). Nevertheless, its implementation in a company has a certain complexity given the interrelationships, mechanisms and instruments that come into play in opportunity identification, viability analysis, development and product launches. It is a complex economic and social phenomenon, but is essential for the survival of activity. In any case, the innovation management has undergone a change. In its early stages it originated from a company-led type of innovation, headed by a research and development department. More recently, Chesbrough (2003) has proposed the gradual opening of a company to its stakeholders, with active listening fostering innovation. The involvement of consumers, distributors, suppliers, and other stakeholders becomes a central part of new product development, and then the concept of Open Innovation (OI) appears.

The implementation of this new innovation management model is boosted by the appearance of social media (Hays et al., 2013). These 2.0 platforms encourage immediate and flexible interaction and collaboration that is necessary to create a space for co-creation between the company and its public (Rohrbeck et al., 2009; Awa, 2010; Chenhall et al., 2011; Su et al., 2015).

Innovation has positive effects on any business activity, but it is especially crucial in the tourism sector due to its contribution to GDP, as well as other factors such as empowerment of the tourist, globalisation, the hostile competitive environment and sustainability. The competitiveness of the sector is mainly determined by innovation, so the European Union in Horizon 2020 emphasises the need to work to foster innovation in order to maintain desirable levels of competitiveness in its member states.

At present there is still little empirical evidence from studies that focus on innovation and tourism (Hjalager, 2010). The situation becomes more worrying if we view open innovation as the new context for the tourism sector (Ramayah, 2011). Nevertheless, studies on social media in the sector have become numerous, as the review by Leung et al. (2013) shows, but investigations that focus on the potential of social media at the service of innovation are scarce. This paper aims to make progress on this field.

For all the above reasons, our objective is to find the extent to which tourism has internalised models of open innovation with the support of social media, and to do this we will look at companies in Portugal and Spain.

This paper is divided into five sections. After this introduction, we focus on the literature that has inspired the proposal of the hypotheses. Next, we explain the methodology, including the sample and the statistical procedure used (cluster analysis). The fourth section deals with the empirical component, and concludes with the evidence from four groups of companies, each one adopting a 
different approach to incorporating the customer into innovation processes and thereby achieving a better competitive position. Additionally, the paper suggests, as a practical implication, the design of strategies for collaborative innovation as a source of competitive advantage, and strengthening of positive relationships and customer loyalty. We end by identifying the limitations and future lines of research.

\section{Literature review and hypothesis}

\subsection{The new paradigm of innovation}

Innovation is the ability of companies to differentiate themselves from others by being permeable to contributions from their stakeholders (Huizingh, 2011). The company gains knowledge by concentrating on internal abilities, studying its competitors, and generating spaces in which to collaborate with other key agents (Keupp \& Gassman, 2009; Croft, 2016). In short, this involves an opening of the organisation, which requires a network of collaborators (Ramayah et al., 2011; Croft, 2016), and makes it possible for New Product Development (NPD)/ New Service Development (NSD) to be participatory and inclusive (Fichter, 2009). A strong commitment to creating processes for open Innovation can give a competitive advantage, but it is also necessary to create added value for all involved (Enkel et al., 2009; Bahemia \& Squire, 2010; Thanasopon et al. 2016). For this reason, it is difficult to manage a systematised model to implement an Innovation paradigm (Keupp \& Gassman, 2009; Chiaroni et al., 2011; Asikainen, 2015).

Innovation is an undeniable factor in the growth and prosperity of territories and organisations (OECD 2013) even in SMEs (van de Vrande et al., 2009). Nevertheless, the strategy adopted by Horizon 2020 emphasises the importance of the service sector and the need to achieve improved economic performance by using innovation as a base (Asikainen, 2015). The OECD (2008, p.11) categorically insists that "Open Innovation needs to be embedded in an overall business strategy that explicitly acknowledges the potential use of external ideas, knowledge and technology in value creation". In this paper, we focus on the tourism sector because it can be considered a differential innovation system in which the implementation of open innovation offers opportunities for companies to adapt to the new tourist profile (Stamboulis \& Skayannis, 2003) and be able to offer unique and innovative experiences (Weiermair, 2006) which connect them better with the market and maintain their competitive standing. In conclusion, we assert that open innovation has become a way to gain a competitive advantage (Hjalager, 2010; Huizingh, 2011) in the tourism sector and to maintain one's position as a leader in the sector by adopting and launching services, products and innovative experiences.

\subsection{Integrated innovation model}

Once innovation is taken on as being key to the development of economic activity, innovation always needs to be a model to support the activity (Chiaroni et al., 2011; Asikainen, 2015). These systems of innovation management are a set of new and existing products with specific uses, interacting with a set of agents oriented to the creation, production and sale of these products in any industry and, in this paper, from the perspective of the tourism sector. In this sense, it is necessary to design one's approach according to the objectives and results desired (Lazzarotti \& Manzini, 2009).

As a basis for this study, we have used Sarkar's Integrated Innovation Model (IIM) (2005), which allows us to understand the dynamics of innovation connected to the market's stakeholders in a sustainable way over time, guaranteeing results in a controlled context.

The model has four dimensions (Figure 1): an archetype space, a strategy space, an outcome space and a market space, which combine to describe an integrated innovation space. Each dimension is represented by a quadrant on the matrix. The vertical and horizontal axes represent on one hand, 
the company's level of innovation and product differentiation, and on the other, the market competitive pressure and the performance in the market.

Figure 1. Integrated innovation model (IIM)

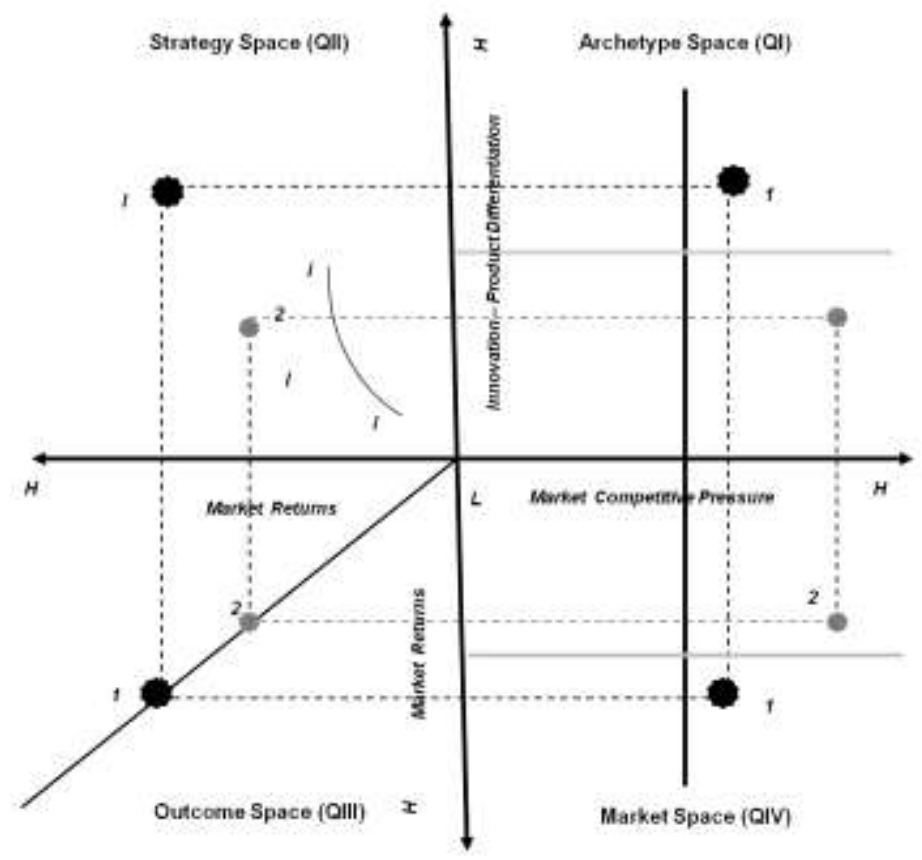

Source: from Sarkar (2005)

Additionally, several elements proposed by Keupp and Gassman (2009) to identify the archetypes of OI are included in this research. The first is the use of open innovation for NPD management and on the other hand, is the intensity of collaboration with the stakeholders, especially with the consumer (tourists).

\subsection{Key elements for open innovation}

For open innovation to work, it requires flexible and bidirectional communication channels with the various stakeholders. The need for open innovation platforms (OIP) and obviously the support of ICTs is evident (Jiménez-Zarco et al., 2011) and social media have all the recommended characteristics to satisfy the following demands (Abbate \& Coppolino, 2011):

- Empower people to use their creativity to solve potential problems and issues (Parameswaran \& Whinston, 2007; Fichter, 2009).

- Support business decision-making through the contributions of stakeholders directly related to the company - in particular, the customers (Croft, 2016).

- Encourage social interactions and coordinate people (Rohrbeck et al., 2009; Battistella \& Nonino, 2012).

- Become an interface for opportunity identification, problem-solving, coordination of sections and promotion of collaborations (Rohrbeck et al., 2009; Battisella \& Nonino, 2012)

Therefore, social media are the ideal source of collaboration for NPD. From the company's point of view, social media provide qualified information about the consumer and show changes in consumer behaviour and preferences in real time. In short, they can be considered an intelligence system for the company. 


\subsection{Research hypotheses}

This research paper poses key questions about open innovation in tourism, focusing on touristic enterprises in Malaga (Spain) and Algarve (Portugal):

Question 1: How does the tourism sector orient innovation and consumer participation in NPD?

Question 2: To what point have social media become a tool to support open innovation?

Question 3: Can we classify tourism companies according to their orientation and behaviour in matters of open innovation?

To answer these questions, we have formulated a series of working hypotheses:

H1 In tourism sector Open Innovation has positive impact on differentiation strategy and engagement with the tourist.

H2 Social media are a support tool for NPD but in tourism companies are still not sufficiently exploited in this direction.

H3 There is a homogenous structure of behaviour that enables us to classify tourism companies according to two main factors:

H3.1 Open innovation implementation.

H3.2 Intensity and use of social media.

\section{Research design and methods}

\subsection{Development of the research instrument}

The design of the questionnaire (Appendix 1) was modelled on Narver and Slater (1990) and Authane-Gima \& Ko (2001), given that these two studies laid the foundations for companies' different orientations to the market, to entrepreneurship, to the competition, and how the combination of these influences the companies' behaviour. In our study, we attempt to classify the tourism companies in the sample according to their permeability to their environment and their level of assimilation of open innovation. The online questionnaire, available in both Portuguese and Spanish, consisted of five blocks:

1. Firm's characteristics (FC).

2. Competitive environment (CE). Three key aspects were analysed: environmental hostility, intensity of market competition and the level of differentiation between competitors.

3. R\&D. This block focussed on understanding the importance of innovation, the effectiveness and perceived profitability of the innovations, and the percentage of turnover occupied by new products, as well as the budget dedicated to $R \& D$.

4. External openness (EO). We wanted to know the degree of openness towards the different stakeholders for NPD. We also measured the relationships between the area of marketing and R\&D (Massey \& Kyriazis, 2007).

5. Customer involvement with social media (CSM). This block shows which social media are used most, as well as the motivations, and when and why they incorporate the consumer into the process of innovation (Awa, 2010). Finally, we assess whether they have a management model of open innovation (Keupp \& Gassman, 2009; Karlsson, 2010).

Nominal variables and Likert scale (1-7) are used in the questionnaire.

\subsection{Data collection and sampling}

Field work took place in 2016, with the first months being used to compile databases and directories of tourism companies in the target zones: the south of Spain and Portugal. The indicators of tourismrelated impact for both locations justify their selection and make them suitable for the subsequent generalisation of results. Spain and Portugal are the two countries that most depend on tourism in Europe; in both cases this economic activity contributes over 9\% of GDP, and accounts for $11 \%$ in Spain, and $8 \%$ in Portugal, of national employment. It is clear that Algarve and the Costa del Sol 
occupy some of the highest positions in the ranking with respect to overall tourism in the country (third and fourth place), (Barreira et al., 2016)

In terms of the volume of operations, Costa del Sol Occidental has 5,000 companies and includes 8 municipalities along the coastal strip, as well as the capital. Algarve, for its part, has 1,000 companies in the 12 municipalities along its coast.

We used a stratified probabilistic random sample that differentiates two groups, corresponding to each zone. The statistical parameters we applied for 6,000 enterprises were $90 \%$ confidence and 7\% error, so the sample consisted of 135 enterprises questionnaires in total (51 for the south of Portugal and 84 for the south of Spain). And so to ensure the representative sample, 200 questionnaires were sent.

\subsection{Multivariate analysis}

We have applied a cluster analysis with the aim of defining structures of behaviour regarding the implementation of open innovation, supported in Keupp and Gassman (2009) and introduced as innovation in the orientation of the use of social media.

\section{Data analysis and results}

\subsection{Descriptive analysis}

Going into detail concerning the relationships between variables and their significance for the population, we will carry out a descriptive analysis of the sample in order to present a general view of its make-up. This section will pay special attention to the items in the firm's characteristics block: activity, turnover and size, according to the number of employees.

With regard to the classification of the activity (Figure 2) we wanted to consider the participation of the tourism sector as a whole, to establish relationships between this variable and the predisposition to open innovation. The distribution of the sample corresponds faithfully to the structure of the tourism sector in the target zones.

Figure 2. Classification of the sample by activity

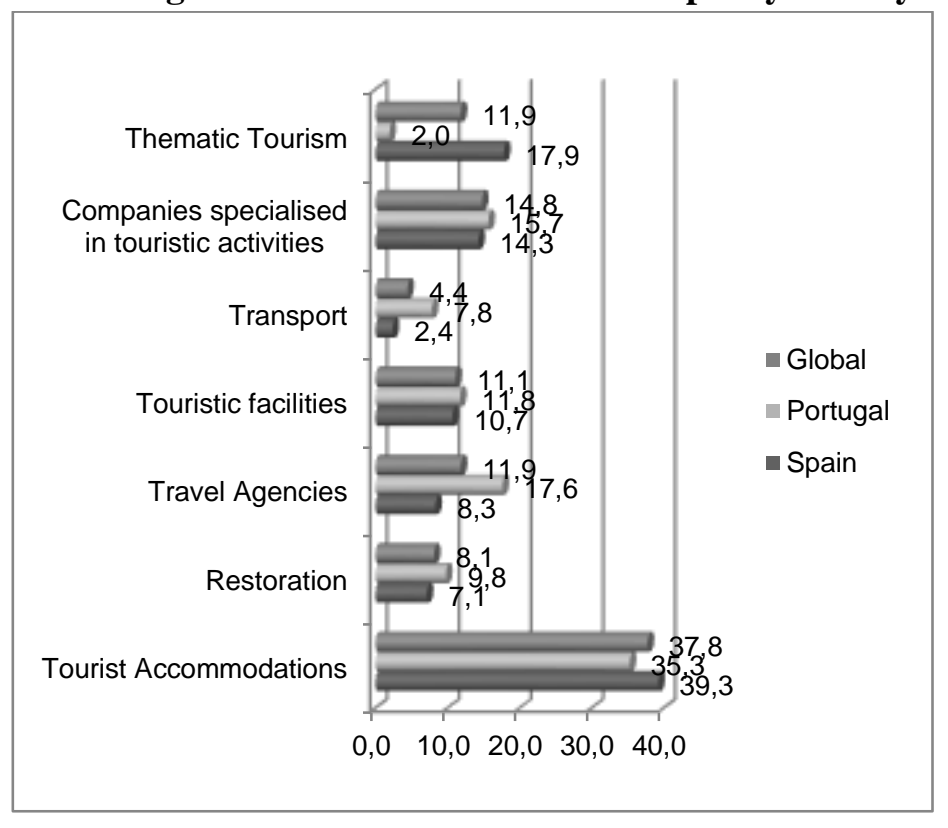

Source: In-house production with SPSS

The variables of turnover and size, according to the number of employees, should be analysed together in order to reveal the structure and characteristics of the productive network. In this network, small businesses are predominant, and authors like van de Vrande et al. (2009) insist upon 
the importance of open innovation in SMEs. Additionally, there is a significant amount of microSMEs, which, with a limited personnel structure and limited economic results, undertake various types of dynamic tourist activities. Figures 3 and 4 show both items.

Figure 3. Distribution of the sample by turnover

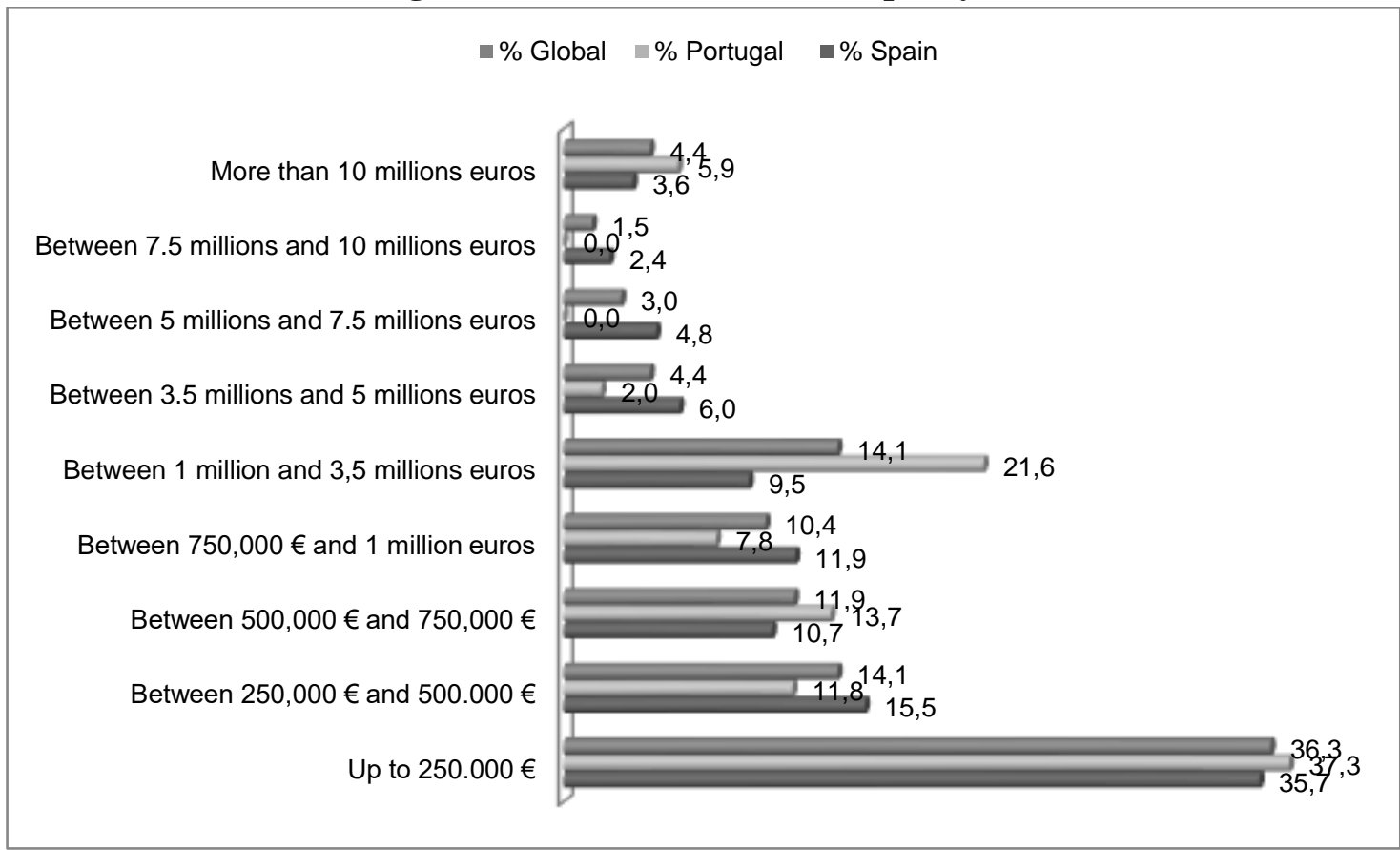

Source: authors compilation with data from SPSS

Figure 4. Distribution of the sample by size (employees)

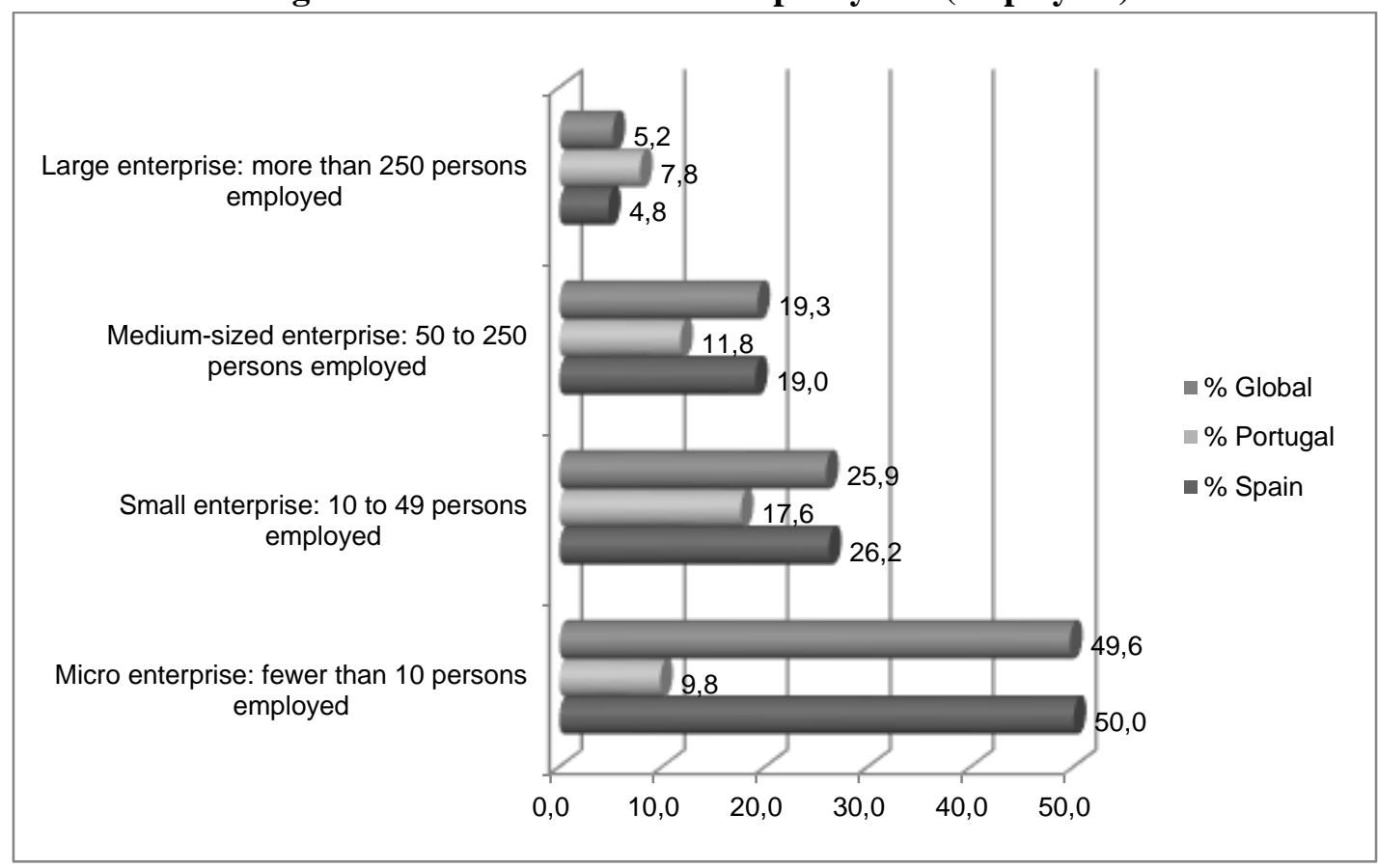

Source: authors compilation with data from SPSS

We will now turn to some of the variables in the "Customer involvement with social media (CSM)" block, since these show us the tourism companies' view of open innovation supported by 2.0 platforms. The use of social media stands out as being imperative for the sector, as is demonstrated 
by the fact that only $2.9 \%$ of the sample admitted to staying away from them, both in the case of Portuguese and Spanish companies. The social network that companies are most familiar with is Facebook. This is followed by the combination of Facebook and Twitter and, probably for strategic positioning reasons, Facebook and GooglePlus. At any rate, it is surprising that more than $68 \%$ of business use two or more social media. Instagram and LinkedIn appear to be becoming more popular, not on their own, but combined with other networks. While Instagram is making progress in both Costa del Sol and the Algarve, LinkedIn is gaining ground in Costa del Sol. The questionnaire also gave the option of indicating other social media, and YouTube and Pinterest stand out, but their penetration is far from that of the major networks and is always a part of a tourism company's digital strategy mix.

Defining a communication strategy in the social media represents a qualitative leap, but its usefulness for NPD and, in general, for making the customer a participant, is s natural evolution towards an open innovation model.

\subsection{Statistical analysis: cluster analysis}

The cluster analysis allows us to develop significant subgroups of tourism companies according to their behaviour in relation to open innovation, mainly based on two main variables: open innovation implementation and intensity and use of social media. The first step in the application of cluster analysis is the selection of variables. In this case we have only used metric variables. Since not all of them conformed to the standard of a 1-7 scale, we started with the detection of atypical cases and standardisation, opting for z-scores as preliminary steps. We performed tests in order to reach the most significant solution, and introduced variables in such a way that the application of the cluster became more and more focused and refined until only variables that demonstrated sufficient differences were involved. The working variables are those related to the open innovation management model (CSM4.1, CSM4.2, CSM4.3, CSM4.4, CSM4.5, CSM4.6), those related to the level of innovation in terms of investment as well as to the proportion of new products in the overall portfolio, (RD4 and RD5) and two metric variables of characteristics (turnover and employees).

The preliminary study of the relationships between the variables led us to carry out the proximity verification with the intergroup linking method using Ward's method. This results in the dendogram shown in Figure 5.

The method indicates that the recommendable number of final conglomerates is somewhere between 2 and 4 (Table 1).

The consolidation of the results led us to use a hierarchical and non-hierarchical procedure (kmeans). The second procedure was used to produce the profiles of the variables. 
Figure 5. Dendogram

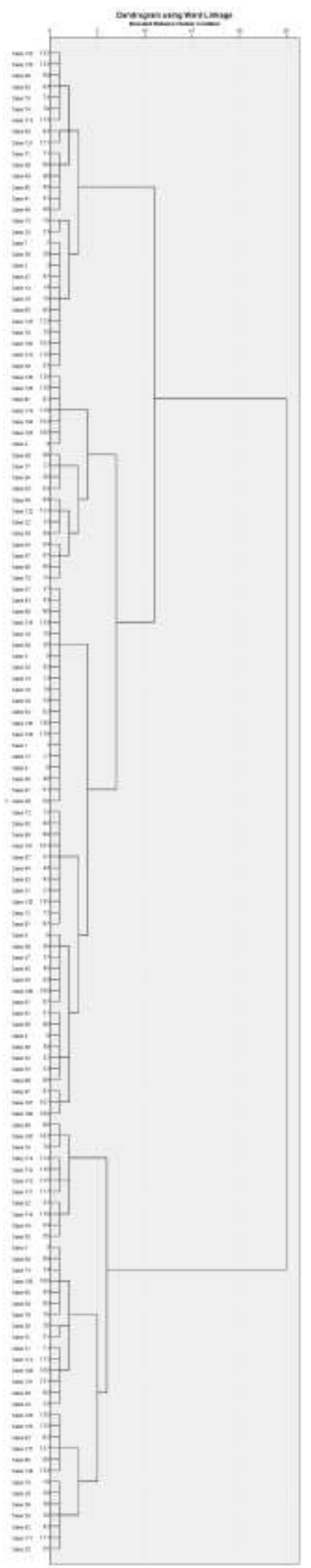

Source: Data from SPSS 
Table 1. Initial centres of the conglomerates

\begin{tabular}{|c|c|c|c|c|}
\hline & \multicolumn{4}{|c|}{ Cluster } \\
\cline { 2 - 5 } & 1 & 2 & 3 & 4 \\
\hline RD4 & 2 & 1 & 2 & 6 \\
CSM4.1 & 2 & 1 & 1 & 4 \\
CSM4.2 & 1 & 2 & 1 & 7 \\
CSM4.3 & 2 & 6 & 1 & 7 \\
CSM4.4 & 1 & 5 & 1 & 7 \\
CSM4.5 & 4 & 2 & 6 & 7 \\
CSM4.6 & 1 & 4 & 1 & 7 \\
CSM5 & 1 & 3 & 7 & 7 \\
FC2 & 1 & 9 & 1 & 1 \\
FC3 & 1 & 3 & 1 & 1 \\
\hline
\end{tabular}

Source: In-house production with SPSS

The iterations history (table 2) highlights that the most significant difference between the groups after several iterations is the solution with four conglomerates. As a result, table 3 shows more differences between groups and only suggests eliminating the variables RD4 and CSM4.4 due to the low differences between two groups and the fact that the greater distance shown in the rest of the variables contradicts this behaviour.

Table 2. Iterations history

\begin{tabular}{|c|c|c|c|c|}
\hline \multirow{2}{*}{ Iteration } & \multicolumn{4}{|c|}{ Change in Cluster Centres } \\
\cline { 2 - 5 } & 1 & 2 & 3 & 4 \\
\hline 1 & 4.974 & 5.013 & 3.856 & 5.673 \\
2 & .453 & .194 & .407 & .192 \\
3 & .263 & .000 & .000 & .076 \\
4 & .000 & .000 & .000 & .000 \\
\hline
\end{tabular}

Source: In-house production with SPSS

Table 3. Final centres

\begin{tabular}{|c|c|c|c|c|}
\hline & \multicolumn{4}{|c|}{ Cluster } \\
\cline { 2 - 5 } & 1 & 2 & 3 & 4 \\
\hline RD4 & 2 & 2 & 2 & 3 \\
RD5 & 2 & 4 & 1 & 2 \\
CSM4.1 & 5 & 4 & 2 & 5 \\
CSM4.2 & 3 & 5 & 2 & 6 \\
CSM4.3 & 3 & 4 & 2 & 5
\end{tabular}




\begin{tabular}{|c|c|c|c|c|}
\hline & \multicolumn{5}{|c|}{ Cluster } \\
\cline { 2 - 5 } & 1 & 2 & 3 & 4 \\
CSM4.4 & 3 & 5 & 4 & 5 \\
CSM4.5 & 4 & 5 & 2 & 6 \\
CSM4.6 & 3 & 4 & 2 & 5 \\
CSM5 & 4 & 5 & 3 & 6 \\
FC2 & 4 & 7 & 2 & 3 \\
FC3 & 2 & 3 & 1 & 2 \\
\hline
\end{tabular}

Source: In-house production with SPSS

The comparison between the means of the clusters with ANOVA (Table 4) demonstrates the significant differences for all the variables.

Table 4. ANOVA

\begin{tabular}{|c|c|c|c|c|c|c|}
\hline \multirow{2}{*}{} & \multicolumn{3}{|c|}{ Cluster } & \multicolumn{2}{c|}{ Error } & \multirow{2}{*}{ S } \\
\cline { 2 - 5 } & Mean Square & Df & Mean Square & Df & F & Sig. \\
\hline RD4 & 3.475 & 3 & 1.322 & 131 & 2.628 & .053 \\
RD5 & 1.959 & 3 & .756 & 131 & 2.590 & .056 \\
CSM4.1 & 74.669 & 3 & 1.280 & 131 & 58.318 & .000 \\
CSM4.2 & 80.323 & 3 & 1.619 & 131 & 49.628 & .000 \\
CSM4.3 & 71.662 & 3 & 1.473 & 131 & 48.656 & .000 \\
CSM4.4 & 38.551 & 3 & 1.777 & 131 & 21.698 & .000 \\
CSM4.5 & 85.570 & 3 & 1.504 & 131 & 56.895 & .000 \\
CSM4.6 & 87.042 & 3 & 1.846 & 131 & 47.155 & .000 \\
CSM5 & 27.582 & 3 & 1.262 & 131 & 21.851 & .000 \\
FC2 & 158.052 & 3 & 2.371 & 131 & 66.658 & .000 \\
FC3 & 18.452 & 3 & .460 & 131 & 40.123 & .000 \\
\hline
\end{tabular}

Source: In-house production with SPSS

Finally, table 5 presents the number of cases that form each conglomerate.

Table 5. Number of cases per conglomerate

\begin{tabular}{|ll|c|}
\hline Cluster & 1 & 37 \\
& 2 & 32 \\
& 3 & 53 \\
& 4 & 13 \\
Valid & & 135 \\
Missing & & 0 \\
\hline
\end{tabular}

Source: In-house production with SPSS 
The identification of different structures of behaviour regarding the implementation of open innovation in the tourism sector in the Algarve and Costa del Sol justifies the application of cluster analysis, both because of the theoretical basis and the empirical evidence resulting from its application.

\subsection{Validity and reliability}

The literature reviewed already guaranteed the validity of the questionnaire, but in addition we validated the internal consistency of the questionnaire as an instrument of investigation by applying Cronbach's alpha for all the factors that formed each of the four main blocks: CE, RD, EO and CSM, exceeding the reference values by 0.90 . In addition, we checked the confidence coefficient for the four dimensions on which the questionnaire is structured and obtained results with a mean of 0.66 ; only the CE block is less than the mean value when taken on its own.

\section{Discussion and conclusions}

Hypothesis 3 set out the possibility of classifying tourism companies according to their implementation of open innovation as well as the intensity and use of social media. Looking at the results, we can perceive four different types of groups of companies (Table 6). The name of each group is based on the work of Sarkar (2005) due to the similarities in the patterns of behaviour. We also find similarities with three archetypes (professionals, explorers and scouts) in Keupp and Gassman's research (2009).

Table 6. Archetypes of the conglomerates

\begin{tabular}{|c|c|c|c|c|}
\hline Variable & $\begin{array}{c}\text { Cluster } 1 . \\
\text { Bear Companies }\end{array}$ & $\begin{array}{c}\text { Cluster } 2 . \\
\text { Wolf Companies }\end{array}$ & $\begin{array}{c}\text { Cluster } 3 . \\
\text { Sheep Companies }\end{array}$ & $\begin{array}{c}\text { Cluster } 4 . \\
\text { Fox Companies }\end{array}$ \\
\hline Volume of turnover $^{1}$ & $€ € €$ & $€ € € €$ & $€$ & $€ €$ \\
\hline $\begin{array}{l}\text { Type of company } \\
\text { (according to } \\
\text { number of } \\
\text { employees) }\end{array}$ & Small business & $\begin{array}{l}\text { Large and medium- } \\
\text { sized companies }\end{array}$ & Microenterprise & Small business \\
\hline $\begin{array}{c}\text { Investment in } \\
\text { innovation as a } \\
\text { percentage of } \\
\text { annual sales (RD5) }\end{array}$ & $\begin{array}{l}\text { Dedicates a low but } \\
\text { stipulated percentage } \\
\text { of its annual volume of } \\
\text { sales. }\end{array}$ & $\begin{array}{l}\text { The annual } \\
\text { investment in } \\
\text { innovation is } \\
\text { medium-high. }\end{array}$ & $\begin{array}{l}\text { The investment in } \\
\text { innovation is very low, } \\
\text { mainly because it does } \\
\text { not respond to an } \\
\text { established pattern } \\
\text { linked to results or sales. }\end{array}$ & $\begin{array}{l}\text { The quantity } \\
\text { dedicated to } \\
\text { innovation is low, but } \\
\text { significant, in } \\
\text { comparison to } \\
\text { overall turnover and } \\
\text { the personnel } \\
\text { structure. }\end{array}$ \\
\hline $\begin{array}{c}\text { Model of open } \\
\text { innovation } \\
\text { (CSM4.1) }\end{array}$ & $\begin{array}{l}\text { Considered to possess } \\
\text { a minimally } \\
\text { systematised model of } \\
\text { open innovation. }\end{array}$ & $\begin{array}{l}\text { A model of Open } \\
\text { Innovation exists, } \\
\text { but still requires } \\
\text { resources, } \\
\text { procedures and time } \\
\text { to develop } \\
\text { completely. }\end{array}$ & $\begin{array}{l}\text { Almost non-existent, } \\
\text { some isolated or very } \\
\text { occasional procedures in } \\
\text { relation to open } \\
\text { innovation but no } \\
\text { defined minimal system } \\
\text { or structure. }\end{array}$ & $\begin{array}{c}\text { They have a } \\
\text { developed model of } \\
\text { open innovation } \\
\text { though there is room } \\
\text { for improvement and } \\
\text { escalation. }\end{array}$ \\
\hline $\begin{array}{l}\text { Mechanisms to } \\
\text { stimulate customer } \\
\text { participation } \\
\text { (CSM4.2) }\end{array}$ & $\begin{array}{l}\text { The mechanisms to } \\
\text { stimulate customer } \\
\text { participation in the } \\
\text { development of new } \\
\text { products are more a } \\
\text { consequence of the } \\
\text { management of } \\
\text { relationships with the } \\
\text { customer than of a } \\
\text { complete awareness of } \\
\text { the need to establish }\end{array}$ & $\begin{array}{l}\text { The mechanisms to } \\
\text { stimulate customer } \\
\text { participation are well } \\
\text { developed. }\end{array}$ & $\begin{array}{l}\text { Customer participation is } \\
\text { barely promoted; rather } \\
\text { the enterprise attends to } \\
\text { the desires of customers } \\
\text { to contribute in } \\
\text { innovation processes } \\
\text { without motivating them } \\
\text { directly. }\end{array}$ & $\begin{array}{l}\text { Stimulation of the } \\
\text { customer is a very } \\
\text { well-defined and } \\
\text { directed element. }\end{array}$ \\
\hline
\end{tabular}

\footnotetext{
${ }^{1}$ Volume of turnover is represented by symbol $€$, so the higher the company's turnover more symbols of $€$ has.
} 


\begin{tabular}{|c|c|c|c|c|}
\hline Variable & $\begin{array}{c}\text { Cluster } 1 . \\
\text { Bear Companies }\end{array}$ & $\begin{array}{c}\text { Cluster } 2 . \\
\text { Wolf Companies }\end{array}$ & $\begin{array}{c}\text { Cluster } 3 . \\
\text { Sheep Companies }\end{array}$ & $\begin{array}{c}\text { Cluster } 4 . \\
\text { Fox Companies }\end{array}$ \\
\hline & $\begin{array}{c}\text { specific mechanisms to } \\
\text { achieve this. }\end{array}$ & & & \\
\hline $\begin{array}{l}\text { Identification of } \\
\text { needs (CSM4.3) }\end{array}$ & $\begin{array}{l}\text { Needs are known in } \\
\text { general terms, } \\
\text { although there is no } \\
\text { system of advanced } \\
\text { diagnosis to use as a } \\
\text { base from which to } \\
\text { direct the lines of } \\
\text { collaborative } \\
\text { innovation. }\end{array}$ & $\begin{array}{l}\text { There is a medium- } \\
\text { high knowledge of } \\
\text { the company's } \\
\text { needs for innovation } \\
\text { and differentiation, } \\
\text { and collaboration } \\
\text { with the consumer is } \\
\text { planned to respond } \\
\text { to them. }\end{array}$ & $\begin{array}{l}\text { Needs for innovation are } \\
\text { not studied. New } \\
\text { products are introduced } \\
\text { as a result of the } \\
\text { environment and not as } \\
\text { a studied process that } \\
\text { starts with a diagnosis } \\
\text { and collaborative } \\
\text { involvement of the } \\
\text { customer. }\end{array}$ & $\begin{array}{l}\text { Needs for innovation } \\
\text { are specifically } \\
\text { studied as a base } \\
\text { from which to design } \\
\text { the processes of } \\
\text { collaborative } \\
\text { involvement with } \\
\text { stakeholders. }\end{array}$ \\
\hline $\begin{array}{l}\text { System of indicators } \\
\text { (CSM4.5) }\end{array}$ & $\begin{array}{l}\text { They have a minimal } \\
\text { structure for a system } \\
\text { of indicators of } \\
\text { collaborative } \\
\text { innovation. }\end{array}$ & $\begin{array}{c}\text { A well-structured } \\
\text { system of indicators } \\
\text { exists. }\end{array}$ & $\begin{array}{c}\text { There are isolated } \\
\text { indicators that confirm } \\
\text { the usefulness of the } \\
\text { efforts in the } \\
\text { management of social } \\
\text { networks and } \\
\text { collaborative innovation, } \\
\text { but they are isolated and } \\
\text { unstructured. }\end{array}$ & $\begin{array}{c}\text { The system of } \\
\text { indicators of open } \\
\text { innovation for this } \\
\text { cluster is more } \\
\text { developed. }\end{array}$ \\
\hline $\begin{array}{l}\text { Establishment of } \\
\text { rewards (CSM4.6) }\end{array}$ & $\begin{array}{c}\text { They have taken the } \\
\text { first steps to establish } \\
\text { parameters to } \\
\text { distinguish valuable } \\
\text { customer contributions } \\
\text { and make them likely } \\
\text { to form a part of NPD, } \\
\text { but the reward system } \\
\text { does still not respond } \\
\text { to just one pattern. }\end{array}$ & $\begin{array}{l}\text { There is a medium- } \\
\text { high level of reward } \\
\text { for the customer but } \\
\text { rewards vary for } \\
\text { contributions which } \\
\text { result in a product } \\
\text { and those that do } \\
\text { not. }\end{array}$ & $\begin{array}{l}\text { There are rewards but } \\
\text { no pattern; nor does the } \\
\text { enterprise seem to } \\
\text { recognise a procedure to } \\
\text { distinguish contributions } \\
\text { that are worthy of } \\
\text { reward. }\end{array}$ & $\begin{array}{l}\text { Not only is there an } \\
\text { awareness of the } \\
\text { need to reward the } \\
\text { most collaborative } \\
\text { customers, but there } \\
\text { is also a system to } \\
\text { identify the } \\
\text { contributions that } \\
\text { can become } \\
\text { innovation by levels. }\end{array}$ \\
\hline
\end{tabular}

Source: In-house production

We would like to end this section by emphasising that tourism companies need to make an effort to create a consistent and well-structured system that can make the most of social media from an open innovation perspective. Although the first experiences are clear, in keeping with the cluster analysis, in conglomerates 4 and 2 they are insufficient, and a management model for collaboration with the customer in innovation processes should be devised. There is no doubt that social media have really achieved in the tourism sector, both for the companies and for the customers, but their potential is still not fully exploited in the most desirable way from an open innovation perspective, thereby confirming hypothesis 2 . Curiously, the sector is fully aware of the influence and abilities that these platforms offer, and they openly manifest their awareness of the better results that can be achieved on several levels when the launch of a tourist product or service is accompanied with collaboration from a customer. All of the above allows us to validate hypotheses 1 .

According to the results of this work, tourism companies are gradually adopting Open Innovation as an element of differentiation and competitiveness (Rohrbeck et al., 2009). In agreement with previous works, the awareness of the usefulness of this philosophy is remarkable but does not always coincide with its capacity to put it into practice (Naver \& Slater, 1990; Chiaroni et al., 2011). The difficulty of aligning the innovation strategy with management and control systems, especially when we refer to the opening of the organization abroad, influences this situation, coinciding with the work of Chenhall et al. (2011).

In any case, it is each company that has the capacity to exploit and maximize the possibilities of Open Innovation, that is why it has been identified conglomerates of different profile that have implemented this model of collaborative innovation in a different way and, consequently with different results and evaluations. We find coincidences with the works developed by Van de Vrande (2009) and Lazzarotti and Manzini (2009). In any case, it is the new type of consumer who is really 
motivating and accelerating the change of collaboration structures in tourism companies ( $\mathrm{Su}$ et al., 2015). On the other hand, as reported in the review of the literature, social media are presented as tools with enormous potential for companies of any dimension and sector, but the application of these in the field of Open Innovation is not very common. In this sense, the relationship between Open Innovation and Social Media is the main contribution of this work. The intensity of use and the approach of social media management positively affects the implementation of Open Innovation and, consequently, the results obtained by the companies (Fichter, 2009; Ramayah et al., 2011; Su et al., 2015).

According to the results obtained, it should be noted that even when tourism companies have not yet obtained a direct return on their use, they perceive the capacity in the medium term. In any case, tourism companies from both Spain and Portugal must advance in the mechanisms of motivation and interaction with consumers if they want to achieve results that are really determinant for their positioning and image, this reflection coincides with the conclusions of the work of Battistella and Nonino (2012).

To conclude, leaving aside the results of the study, we should emphasize that this study develops contributions derived from its approach. First, Open Innovation is analyzed in a sector that is scarcely covered by literature (Hossain \& Anees-ur-Rehman, 2015), thus satisfying the demand to develop works that are not mainly focused on industry and technology companies (Huizingh, 2011). This issue also allows us to deepen the influence of the particular nature of the tourism sector. Also, the international comparison between companies brings added value to the analysis of the phenomenon also posed as a future line of research in this field by other authors such as Hossain and Anees-ur-Rehman (2015).

On the other hand, using the cluster analysis allows us to use a relatively simple statistical technique to identify homogeneous behavioral structures among tourism companies in order to advance in the second phase, no longer exploratory, to progress in the detection of cause-effect relationships as well as modeling with more complex techniques such as as SEM. In short, the results are supported by a quantitative empirical work and the identified key issues are useful for a first approach to the Open Innovation phenomenon with the support of social media as well as to pose concrete practical implications to the sector and to reflect on future lines of research.

\subsection{Practical implications}

It is necessary to keep advancing in the analysis of the open innovation phenomenon and its effects on competitiveness, both from the point of view of the investigation and of tourism companies. Regarding the latter, a concerted effort is necessary to create structured models for the management of co-creation spaces in order to obtain the maximum benefits from social media and consolidate open innovation.

\subsection{Limitations and future research directions}

The limitations identified comprise the basis for the design of future lines of research. Firstly, since this is an exploratory study of the behaviour of the tourism sector in open innovation, it is not possible to measure development in the medium term, and a lengthier study is needed in order to advance. Secondly, research has only focussed on the tourism sector, so in the future it would be of interest to make comparisons with other branches of activity, as well as the tourism sectors of other regions.

\section{References}

Abbate, T., \& Coppolino, R. (2011). Knowledge creation through knowledge brokers: some anecdotal evidence. Journal of Management Control, 22, 3, 359-371. doi: 10.1007/s00187-011$0144-5$ 
Asikainen, A. L. (2015). Innovation modes and strategies in knowledge intensive business services. Service Business, 9, 77-95. doi:10.1007/s11628-013-0219-5

Authane-Gima, K., \& Ko, A. (2001). An empirical investigation of the effect of market orientation and entrepreneurship orientation alignment on product innovation. Organization Science, 1, 12, 54 74. doi:10.1287/orsc.12.1.54.10121

Awa, O. (2010). Democratizing the new product development process: a new dimension of value creation and marketing concept. International Business Research, 3, 2, 49-59. doi: 10.5539/ibr.v3n2p49

Bahemia, H., \& Squire, B. (2010). A contingent perspective of open innovation in new product development projects. International Journal of Innovation Management, 14, 4, 603-627. doi: 10.1142/S1363919610002799

Barreira, A.P., Cesario, M., \& Noronha, M.T (2016), Pull attributes of the Algarve: The tourists'view. Tourism Planning \& Development, 14, 1, 87-89. doi: 10.1080/21568316.2016.1192057

Battistella, C., \& Nonino, F. (2012). Open innovation web-based platforms: the impact of different forms of motivation on collaboration. Innovation: Management, Policy \& Practice, 14, 4, 557-575. doi: 10.5172/impp.2012.14.4.557

Chenhall, R. H., Hallunki, J., \& Silvola, H. (2011). Exploring the relationships between strategy, innovation and management control systems: the roles of social networking, organic innovative culture, and formal controls. Journal of Management Accounting Research, 23, 10, 99-128. doi: 10.2308/jmar-10069

Chesbrough, H. (2003). Open Innovation -The New Imperative for Creating and Profiting from Technology. Boston, MA: Harvard Business School Press.

Chiaroni, D., Chiesa, V., \& Frattini, F. (2011). The open innovation journey: how firms dynamically implement the emerging innovation management paradigm. Technovation, 31, 1, 34-43. doi: 10.1016/j.technovation.2009.08.007

Croft, C. D. (2016). Hearing the authentic voice of stakeholders? Implications for governance of tourism strategy-making. Current Issues in Tourism, 2, 2, 1-20. doi: 10.1080/13683500.2016.1153051

Enkel, E., Gassmann, O., \& Chesbrough, H. (2009). Open R\&D and open innovation: exploring the phenomenon. $R \& D$ Management, 39, 4, 311-316. doi 10.1111/j.1467-9310.2009.00570.x

Fichter, K. (2009). Innovation communities: the role of networks of promotors in open innovation, $R \& D$ Management, 39, 4, 357-365. doi: 10.1111/j.1467-9310.2009.00562.x

Hays, S., Page, S. J., \& Buhalis, D. (2013). Social media as a destination marketing tool: its use by national tourism organisations. Current Issues in Tourism, 16, 3, 211-239. doi $10.1080 / 13683500.2012 .662215$

Hjalager, A. M. (2010). A review of innovation research in tourism. Tourism Management, 31, 1, 1-12. doi 10.1016/j.tourman.2009.08.012

Hossain, M., \& Anees-ur-Rehman, M. (2015). Open innovation: An analysis of twelve years of research. Strategic Outsourcing: An International Journal, 9, 1, 22-37. doi 10.1108/SO-09-20150022

Huizingh, E. K. R. E. (2011). Open innovation: state of the art and future perspectives. Technovation, 31, 1, 2-9. doi:10.1016/j.technovation.2010.10.002

Jiménez-Zarco, A. I., Martínez-Ruiz, M. P., \& Izquierdo-Yusta, A. (2011). Key service innovation drivers in the tourism sector: empirical evidence and managerial implications. Service Business, 5, 339-360. doi: 10.1007/s11628-011-0118-6

Karlsson, M. (2010). Collaborative idea management: using the creativity of crowds to drive innovation. Innovation Management, 1, 3-27.

Keupp, M., \& Gassman, O. (2009). Determinants and archetype user of Open Innovation, $R \& D$ Management, 4, 39, 331-341.doi:10.1111/j.1467-9310.2009.00563.x 
Lazzarotti, V., \& Manzini, R. (2009). Different modes of open innovation: a theoretical framework and an empirical study. International Journal Innovation Management, 13, 615-636. doi 10.1142/S1363919609002443

Leung, D., Law, R., Van Hoof, H., \& Buhalis, D. (2013). Social media in tourism and hospitality: a literature review. Journal of Travel \& Tourism Marketing, 30, 1-2, 3-22. doi:10.1080/10548408.2013.750919

Massey, G. R., \& Kyriazis, E. (2007). Interpersonal trust between marketing and R\&D during new product development projects. European Journal of Marketing, 41, 9/10, 1146-1172. doi: $10.1108 / 03090560710773381$

Narver, J., \& Slater, F. (1990). The effect of a market orientation on business profitability. Journal of Marketing, 54, 4, 20-27. doi:10.2307/1251757

OECD (2008) Annual Report. Paris: OECD Publishing.

OECD (2013) Science, Technology and Industry Scoreboard, Innovation for Growth. Paris: OECD Publishing.

Parameswaran, M., \& Whinston, A. B. (2007). Social computing: an overview. Communications of the Association for Information Systems, 19, 762-780.

Ramayah, T., Chow Lee, J. W., \& Chyaw, J. B. (2011). Network collaboration and performance in tourism sector. Service Business, 5, 411-429. doi: 10.1007/s11628-011-0120-z

Rohrbeck, R., Hölzle, K., \& Gemüden, H. G. (2009). Opening up for competitive advantage - How Deutsche Telekom creates an open innovation ecosystem. $R \& D$ Management, 39, 4, 420-429. doi: 10.109/DEST.2013.6611336

Sarkar, S. (2005). Innovation and market structures: an integrated approach. International Journal of Entrepreneurship and Innovation Management, 5, 5/6, 366-378. doi: 10.1504/IJEIM.2005.006994

Stamboulis, Y., \& Skayannis, P. (2003). Innovation strategies and technology for experience-based tourism. Tourism Management, 24, 1, 35-43. doi: 10.1016/S0261-5177(02)00047-X

Su, C. J., Lebrun, A. M., Bouchet, P., Wang, J. R., Lorgnier, N., \& Yang, J. H. (2015). Tourists' participation and preference-related belief in co-creating value of experience: a nature-based perspective. Service Business, 5, 1-24. doi: 10.1142/S1363919609002443

Thanasopon, B., Papadopoulos, T., \& Vidgen, R. (2016). The role of openness in the fuzzy frontend of service innovation. Technovation, 47, 32-46. doi: 10.1016/j.technovation.2015.11.007 van de Vrande, V., de Jong, P. J., Vanhaverbeke, W., \& de Rochemont, M. (2009). Open innovation in SMEs: trends, motives and management challenges. Technovation, 29, 6-7, 423437. doi: 10.1016/j.technovation.2008.10.001

Weiermair, K. (2006). Product improvement or innovation: what is the key to success in tourism? Innovation and Growth in Tourism, OECD, Paris, 53-69. doi: 1016/j.sbspro.2013.12.862 